\title{
Biomarkers of immunotherapy in non-small cell lung cancer (Review)
}

\author{
LINGLING WANG $^{1^{*}}, \mathrm{YUE} \mathrm{HU}^{2^{*}}$, SHENGCHAO WANG $^{3 *}$, JIALI SHEN $^{2}$ and XIAOCHEN WANG ${ }^{1,4}$ \\ ${ }^{1}$ Department of Surgical Oncology, Second Affiliated Hospital, Zhejiang University School of Medicine; \\ ${ }^{2}$ Key Laboratory of Respiratory Disease of Zhejiang Province, Department of Respiratory and Critical Care Medicine, Second \\ Affiliated Hospital of Zhejiang University School of Medicine, Hangzhou, Zhejiang 310009; ${ }^{3}$ Department of Gynecological \\ Oncology, Women's Hospital, Zhejiang University School of Medicine, Hangzhou, Zhejiang 310006; \\ ${ }^{4}$ Department of Breast Surgery, Zhejiang Provincial People's Hospital, People's Hospital of \\ Hangzhou Medical College, Hangzhou, Zhejiang 310014, P.R. China
}

Received December 1, 2019; Accepted June 24, 2020

DOI: $10.3892 / 01.2020 .11999$

\begin{abstract}
Immunotherapy has markedly improved the survival rate of patients with non-small cell lung cancer (NSCLC) and has introduced a new era in lung cancer treatment. However, not all patients with lung cancer benefit from checkpoint blockade, and some suffer from notable immunotoxicities. Thus, it is crucial to identify potential biomarkers suitable for screening the population that may benefit from immunotherapy. Based on the current clinical trials, the aim of the present study was to review the biomarkers for immune checkpoint inhibition, as well as other effective, invalid and hyperprogression markers that may have the potential to better predict responders to immunotherapy among patients with NSCLC. All these biomarkers may be incorporated into the predictive utility of bio-score systems and decision-making algorithms, to better guide the application of immunotherapy in the clinical setting.
\end{abstract}

Correspondence to: Dr Yue Hu, Key Laboratory of Respiratory Disease of Zhejiang Province, Department of Respiratory and Critical Care Medicine, Second Affiliated Hospital of Zhejiang University School of Medicine, 88 Jiefang Road, Hangzhou, Zhejiang 310009, P.R. China

E-mail: huyue88@zju.eu.cn

Dr Xiaochen Wang, Department of Surgical Oncology, Second Affiliated Hospital, Zhejiang University School of Medicine, 88 Jiefang Road, Hangzhou, Zhejiang 310009, P.R. China

E-mail: wangxiaochen@zju.edu.cn

"Contributed equally

Abbreviations: APC, antigen-presenting cell; CTLA-4, cytotoxic T-lymphocyte-associated antigen 4; IFN- $\gamma$, interferon $\gamma$; NK, natural killer; PD-1, programmed death 1; PD-L1, programmed death ligand 1; TIL, tumor-infiltrating lymphocytes; TMB, tumor mutational burden

Key words: biomarkers, immunotherapy, non-small cell lung cancer, immune checkpoint inhibition

\section{Contents}

1. Introduction

2. Overview of immunotherapy in non-small cell lung cancer

3. Predictors of immunotherapy

4. Conclusions and future perspectives

\section{Introduction}

Lung cancer ranks first in morbidity and mortality rate among malignant tumors in both the United States and worldwide (1). Lung cancer is subdivided into two major categories: Non-small cell lung cancer (NSCLC), which accounts for $80-85 \%$ of all lung cancer cases, and small-cell lung cancer (2). The prognosis for patients with stage IV NSCLC is extremely poor, with reported 5-year overall survival (OS) rate of 1 to $8 \%$ in the United States in 2018 (3). Platinum-based chemotherapy has historically been the standard first-line treatment for metastatic NSCLC, although responses to these agents only range between $15-30 \%$, with a relatively short interval until disease progression (4,5). More recently, immunotherapy has emerged as a promising treatment alternative for patients without an actionable driver mutation and has markedly altered the therapeutic approach to advanced NSCLC (6). It has been demonstrated that with immunotherapy, the 5-year survival rate of patients with advanced NSCLC increased from 4.7 to $16 \%$ in the United States in 2018 (3). A recent clinical trial also indicated that nivolumab treatment improved long-term OS rate and achieved durable responses in a proportion of patients with pretreated advanced NSCLC (3). Unlike traditional therapies for NSCLC, immune therapies exploit the host immune system to monitor and destroy cancer cells via the upregulation of key immune checkpoints; at present, NSCLC immunotherapy mainly refers to immune checkpoint inhibitors (ICIs) and anti-programmed cell death protein 1 (PD-1)/programmed death-ligand 1 (PD-L1) agents $(7,8)$.

Patients with metastatic NSCLC generally benefit from immunotherapy; however, a number of patients may not respond to therapy, exhibit a shorter lifetime with treatment 
or suffer major life-threatening immunotoxicities $(9,10)$. Immune therapies lack specific biomarkers compared with the precision of targeting genes due to the complex interactions between tumors and the immune system. Furthermore, the response to immunotherapy also varies according to the tumor characteristics $(9,10)$. Apart from immune-associated adverse events, such as dermatitis, enteritis and hepatitis, some patients may experience clinical manifestations such as 'pseudoprogression' (PP) or 'hyperprogressive' disease (HPD) (11). PP is connected with infiltrations of active T cells and other immune cells within the lesion (12), whereas HPD is defined as a rapid increase in tumor growth rate (minimum two-fold) compared with the expected growth rate (13).

Considering both the advantages and disadvantages of immunotherapy, it is only suitable for a small number of patients (14). Moreover, indiscriminate application may significantly increase the incidence of adverse reactions. Therefore, it is crucial to establish biomarkers predictive of the response of patients with NSCLC to immunotherapy. As a result, studying host-tumor interactions and identifying predictive biomarkers for the response to immune checkpoint blockade treatment is essential for enhancing the efficacy of immunotherapy agents. In the present article, the currently approved biomarkers for immune checkpoint inhibition in NSCLC are reviewed, and the emerging effective, invalid and HPD markers are highlighted. In addition, the identification of biomarkers that predict treatment responses, and the development of rational therapeutic combinations that could enhance the efficacy of immune checkpoint blockade, are discussed.

\section{Overview of immunotherapy in non-small cell lung cancer}

As the understanding of lung cancer has increased, the concept of treatment has also changed. Traditional treatments for lung cancer have some insurmountable barriers. For example, molecular targeting drugs may not be effective when genomic testing reveals no targetable alteration, such as epidermal growth factor receptor (EGFR) mutations, anaplastic lymphoma kinase (ALK) or ROS1 translocation/re-arrangements (15). As traditional methods have been shown as ineffective against certain cancer types, the focus has shifted to immune cells, and immunotherapy for lung cancer is attracting increasing attention. In particular, reactivating immune cells to clear cancer cells and stopping cancer cell immune evasion are focuses of this research (16).

Immunotherapy is a process of continuous responses by activating the body's immune system to attack and kill tumor cells. First, the antitumor immune response is enhanced and prolonged by persistent recognition and memory of tumor antigens (16). Subsequently, certain cytotoxic T cells differentiate into natural memory $\mathrm{T}$ cells, which can provide long-term immune memory protection, even in the absence of the original antigen stimulation (16). Therefore, immunotherapy is more likely to achieve long-term survival compared with conventional treatments (17).

The immunotherapy of lung cancer is subdivided into active and passive immunotherapy. The former enhances the antitumor effect of the body by activating the patient's own immune response, and mainly includes vaccines and immunoregulatory agents. The latter provides patients with products such as anti-PD-1 and anti-PD-L1 antibodies of the immune response to enhance the body's antitumor response, mainly through adoptive cellular immunotherapy (18). When it comes to the most successful immunotherapy, ICIs have been attracting increasing attention. Immune checkpoints are important inhibitory pathways for controlling the duration and magnitude of the immune response. Tumors can use these pathways to resist immune responses. ICIs have the ability to interfere with tumor resistance and enhance the body's immune response to tumor cells, including first-generation anti-cytotoxic T lymphocyte antigen 4 (CTLA-4) antibodies, second-generation anti-PD-1 antibodies and anti-PD-L1 antibodies (7). Second-generation ICIs are more selective and safer compared with first-generation ICIs (19).

CTLA-4 checkpoint inhibitors. Normally, activation of $\mathrm{T}$ lymphocytes requires the joint activation of two signaling pathways: The binding of the $\mathrm{T}$ cell receptor to the major histocompatibility complex-antigen peptide complex presented by antigen-presenting cells (APCs), and the binding of the B7 molecule (B7-1 or B7-2) to CD28 on the surface of T cells (20). CTLA-4 is expressed exclusively on the surface of T cells, where it has a higher affinity to B7 than CD28, and exerts the opposite function compared with CD28 (21). CTLA-4 competes with the costimulatory receptor CD28 for binding to the same ligands, resulting in downregulation of immune response (22). A previous study found that CTLA-4 was abnormally highly expressed on the surface of tumor-infiltrating $\mathrm{T}$ regulatory cells (Tregs), and its expression level in lymph nodes and tumor cells was significantly higher compared with that of peripheral Tregs and effector $\mathrm{T}$ cells (23). Tregs, a subgroup of $\mathrm{CD}^{+} \mathrm{T}$ cells with notable immunosuppressive effects, can inhibit the immune response of other cells. This inhibitory function of Tregs depends heavily on CTLA-4. Thus, anti-CTLA-4 agents binding to CTLA-4 molecules can lead to Treg depletion or functional blockade, thereby contributing to $\mathrm{T}$ cell activation and immunological responses in cancer (24). Currently, there are two main types of antibodies targeting CTLA-4: Ipilimumab and tremelimumab $(23,24)$. Ipilimumab has been approved by the U.S. Food and Drug Administration (FDA) as the first ICI for advanced melanoma based on several clinical trials, despite poor results in lung cancer (25). A randomized phase III trial demonstrated that ipilimumab in combination with chemotherapy did not markedly improve OS compared with chemotherapy alone in the first-line treatment for patients with advanced squamous NSCLC (26).

PD-1/PD-L1 checkpoint inhibitors. PD-1, also known as CD279, is a monomeric glycoprotein and a member of the CD28 superfamily. It is expressed on the surface of activated $\mathrm{T}$ cells, B cells, natural killer (NK) cells, dendritic cells and macrophages (27). PD-L1 is a ligand of PD-1 that is highly expressed in various tumor cells, such as lung cancer, malignant brain tumor and melanoma cells (28). The upregulation of PD-1 ligands in the tumor microenvironment and the connection of PD-1 to its ligands on tumor-specific T cells are the key mechanisms of escaping immune elimination (27-32). For example, PD-1 expressed on $\mathrm{CD}^{+}$and $\mathrm{CD}^{+} \mathrm{T}$ cells, as well as other immune cells, interacts with PD-L1. This leads to decreased activation, proliferation, survival, persistence and 
effector functions of $\mathrm{T}$ lymphocytes, induces antigen-specific $\mathrm{T}$ cell apoptosis and modulates the activity of $\mathrm{CD}^{+}$and $\mathrm{CD}^{+} \mathrm{T}$ cells, NK cells and macrophages, thereby affecting cancer progression in vitro and in vivo (29-31). PD-L1 can be recognized by $\mathrm{T}$ cells, resulting in the release of cytokines, which not only attract other cytotoxic immune cells, but can also induce the expression of the checkpoints that promote immune resistance, including the metabolic reprogramming, differentiation characteristics and promotion of homeostatic proliferation of $\mathrm{T}$ cells (32-34).

In recent years, a growing body of evidence has shown the efficacy of PD-1/PD-L1, particularly in tumor immunotherapy. To date, the FDA has approved four immunosuppressive agents for NSCLC: Two anti-PD-1 (nivolumab and pembrolizumab) and two anti-PD-L1 (atezolizumab and durvalumab) agents. Four clinical trials (CheckMate-017, CheckMate-057, KEYNOTE-010 and OAK) have confirmed that the immunotherapy group had different benefits in terms of efficacy and survival in the second-line treatment setting of NSCLC compared with the chemotherapy group $(14,35,36)$. Moreover, a phase III trial (KEYNOTE-024) revealed that progression-free survival (PFS) or OS with first-line pembrolizumab treatment for NSCLC expressing PD-L1 with a tumor proportion score $\geq 50 \%$, were superior to those with first-line standard platinum-based chemotherapy (37). Based on results of KEYNOTE-042, in 2019 the FDA approved pembrolizumab as first-line treatment for patients with PD-L1 expression $\geq 1 \%$, EGFR mutation-negative and ALK-negative advanced NSCLC (38-40). An interim analysis from the LCMC3 multicenter study at the 2019 World Conference on Lung Cancer confirmed that atezolizumab achieved over half of the pathological remissions in $49 \%$ of the patients with NSCLC on neoadjuvant therapy, suggesting the great potential of immunotherapy in the neoadjuvant setting for lung cancer (41). The clinical studies of IMpower130 and KEYNOTE-189 reported that the PFS or OS of lung cancer were significantly improved with the synergistic effect of immunotherapy combined with chemotherapy $(42,43)$. The PACIFIC study demonstrated that durvalumab conferred OS benefits to patients with unresectable stage III NSCLC after chemoradiotherapy (44). IMpower150 indicated that immunotherapy combined with antiangiogenic agents and chemotherapy improved survival rates as a first-line treatment for advanced non-squamous NSCLC (45). The addition of atezolizumab to bevacizumab plus chemotherapy significantly improved PFS and OS among patients with metastatic non-squamous NSCLC, regardless of PD-L1 expression and EGFR or ALK genetic alteration status (45).

The mechanism of action of the CTLA-4 and PD-1 antibodies differs $(46,47)$. A number of experiments have confirmed that the two antibody types enhance the antitumor effect through complementary mechanisms, and the combined treatment of dual immune drugs has also achieved promising results $(48,49)$. The Checkmate-227 study first demonstrated that nivolumab combined with ipilimumab conferred a significant PFS and reduced the side effects as first-line treatment for patients with advanced NSCLC compared with chemotherapy (50).

Currently, pembrolizumab, nivolumab and atezolizumab, which target the PD-1/PD-L1 axis, are associated with a significant improvement in OS and durable antitumor responses in advanced NSCLC (37,51-53). For unresectable stage III NSCLC, the PACIFIC trial established durvalumab as a new standard for consolidation therapy, which involves continuous maintenance therapy in patients with stable disease and follow-up treatment (44). The preliminary data from several ongoing trials evaluating immunotherapy in the treatment of early and locally advanced lung cancer are promising. However, whether utilizing immune therapy in patients with early-stage NSCLC will improve survival remains uncertain.

For the aforementioned reasons, studying host-tumor interactions and establishing biomarkers to predict response to immune checkpoint inhibition are crucial steps towards using the new panel of immunotherapy agents in the most effective manner (Fig. 1). The aim of the present study was to review the biomarkers for immune checkpoint inhibition, as well as other effective, invalid and HPD markers that may have the potential to better predict responders to immunotherapy in NSCLC (Table I).

\section{Predictors of immunotherapy}

Predictors of effective immunotherapy. The predictive value of PD-L1 and tumor mutational burden (TMB) in lung cancer has been tested in several clinical trials (54). Facing the challenge of adaptability and dynamic changes of the immune system, combined application of biomarkers and dynamic monitoring are expected to become a popular trend of immunotherapeutic research in the future. In addition, in order to overcome the limitations of tissue sample testing, new test methods are emerging (55).

PD-L1 expression levels. The expression of PD-L1 may be a better predictive biomarker that exhibits a stronger association with the antitumor response compared with PD-1 (56). The results of KEYNOTE-024 suggested that patients with advanced NSCLC with high PD-L1 expression ( $\geq 50 \%$ ) had a superior OS with pembrolizumab compared with chemotherapy (37). Data from KEYNOTE-042 indicated that the efficacy of immunotherapy was comparable to that of chemotherapy when patient expression of PD-L1 was 1-49\%. Therefore, the higher the expression of PD-L1, the better the treatment effect of immunotherapy in NSCLC (38).

CheckMate017 and OAK reported that the expression levels of PD-L1 in tumor cells may not be a suitable biomarker for predicting the efficacy of immunotherapy $(35,52)$. This may be because certain signaling pathways promote the malignant behavior of the cancer cell, such as EGFR, mitogen-activated protein kinase (MAPK) and phosphatidylinositol-3-kinase-protein kinase (PI3K-AKT). Conversely, inflammatory response cytokines, particularly interferon (IFN)- $\gamma$, induce and stimulate PD-L1 expression in tumor cells and other types of cells in the immune microenvironment (57). In addition, different detection platforms and evaluation systems have different positive critical values, and there is no consistent standard to measure the expression of PD-L1 in tumor cells (58). Therefore, diverse biopsy sites, primary lesions, metastatic lesions and early treatment may affect the dynamic change in PD-L1 expression, and a single biopsy cannot reflect the whole picture of the tumor. 


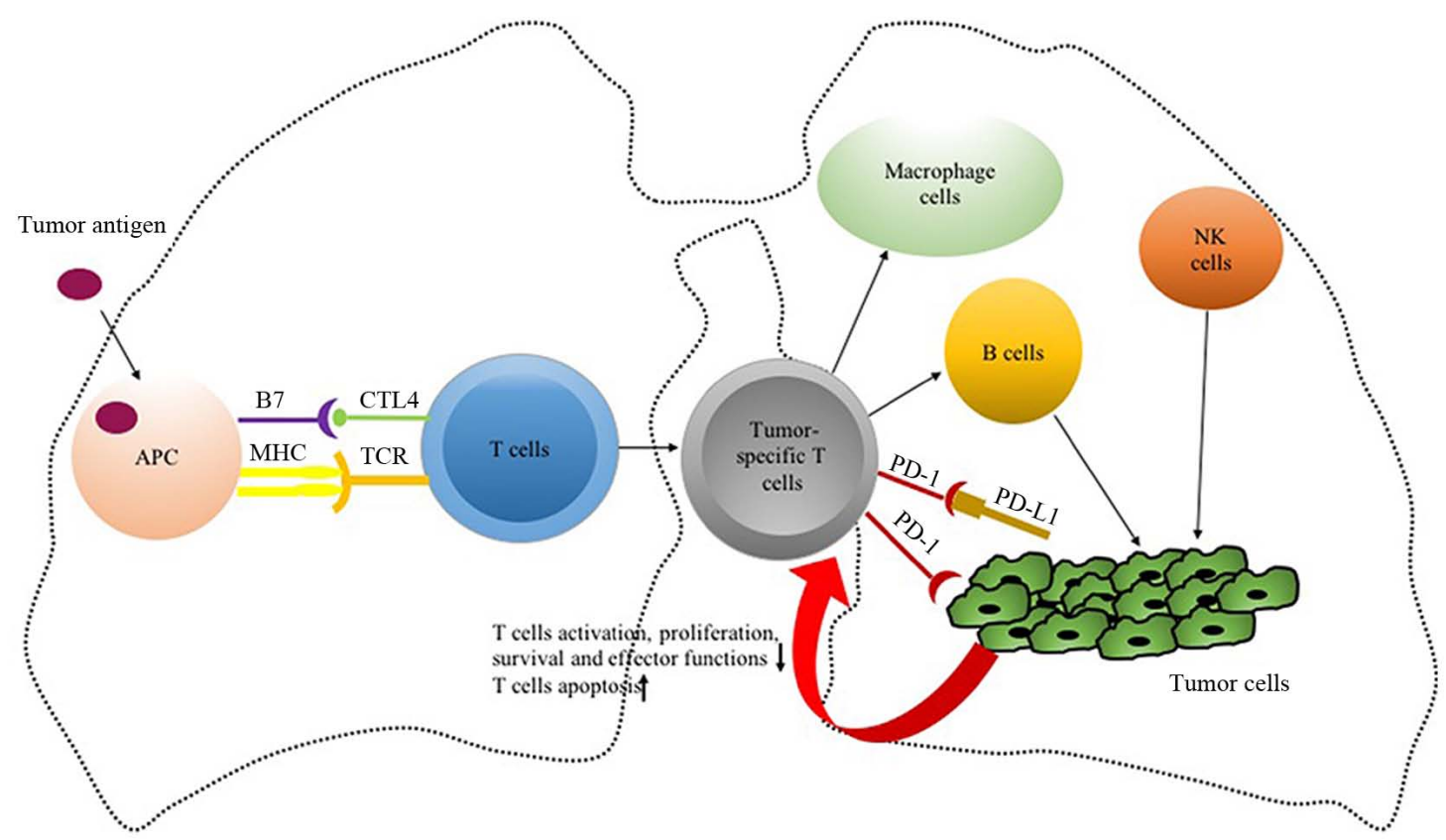

Figure 1. Host-tumor interactions for immunotherapy. APC, antigen-presenting cell; CTLA-4, cytotoxic T lymphocyte-associated antigen 4; MHC, major histocompatibility complex; NK cells, natural killer cells; PD-1, programmed death 1; PD-L1, programmed death ligand 1; TCR, T cell receptor; TILs, tumor-infiltrating lymphocytes.

The expression of PD-L1 may be a suboptimal marker for predicting the therapeutic efficacy of NSCLC immunotherapy, but PD-L1 is currently the most established and widely used biomarker for the clinical immunotherapy of NSCLC $(14,35,37$, $40,42,43-45,51-53,59,60)$.

$T M B$ and neoantigen burden. TMB is defined as the total number of mutations, including replacement and insertion/deletion, per Megabyte of exonic regions of the evaluated genes in the tumor specimen (mut/Mb). Mutations in somatic cells can be transcribed/expressed into RNA/protein levels, producing neoantigens, protein fragments or peptides; these new products are recognized by the immune system as non-autoantigens, activating $\mathrm{T}$ cells and eliciting an immune response (61). Tumors are attacked by a large number of tumor-specific $\mathrm{T}$ cells in patients with a high TMB (TMB-H) (61). The response to anti-PD-1/PD-L1 therapy depends on the numbers of tumor-specific T cells (61). Therefore, tumors with TMB-H are more sensitive to anti-PD-1/PD-L1 treatment, suggesting that TMB and neoantigen burden may be considered as therapeutic biomarkers of immunotherapy (62).

A previous study summarized the association between TMB level and the effective rate of anti-PD-1 therapy in 27 different types of tumors, and demonstrated that the level of TMB was different among diverse tumors (63). Among those treated with anti-PD-1/PD-L1 inhibitors, the objective response rate (ORR) of each tumor type was positively correlated with the level of TMB. The higher the level of TMB expression, the greater the therapeutic effect of PD-1/PD-L1 inhibitors. Previous studies have also reported that patients with TMB-H have a high response rate to anti-PD-1/PD-L1 immunotherapy (61-64). CheckMate026 revealed that the ORR of nivolumab was significantly higher (47 vs. $28 \%$ ) and the PFS was markedly prolonged (9.7 vs. 5.8 months) in the
TMB-H arm compared with that of platinum-based chemotherapy (59). CheckMate227 reported that the PFS of patients with TMB-H $(\geq 10$ mut/Mb) treated with nivolumab and ipilimumab was superior to that of chemotherapy (43 vs. 13\%, respectively) (64). Surprisingly, in the same clinical trial, PFS was improved in CheckMate 227 regardless of PD-L1 expression. CheckMate012 and CheckMate026 also observed no notable correlation between TMB and PD-L1 expression, indicating that TMB was an independent marker of immunotherapeutic response (65). Another study demonstrated that PD-L1 levels combined with TMB could better predict the efficacy of immunotherapy (66); compared with patients with both low expression of PD-L1 and TMB-L, the clinical benefit rate among those with high expression of PD-L1 and TMB-H was $50 \%$ (66). A similar conclusion was reached by CheckMate026 (59).

The POPLAR study analyzed the association between blood TMB (bTMB) and clinical benefit. For bTMB $\geq 10, \geq 16$ and $\geq 20$, patients treated with atezolizumab had an increased PFS and OS compared with docetaxel, and the greatest benefits were obtained when $\mathrm{bTMB} \geq 16$ (53). The OAK study further verified that atezolizumab was associated with a PFS benefit, with a hazard ratio of 0.65 vs. 0.98 for bTMB $\geq 16$ vs. $<16$, respectively (35).

Overall, TMB is considered as a good predictor in immunotherapy. As an emerging biomarker, TMB may be used to screen patients who may benefit from anti-PD-1/PD-L1 immunotherapy.

Tumor-infiltrating lymphocytes (TILs). As the function of PD-1/PD-L1 inhibitors also requires the involvement of lymphocytes near the tumor, the abundance of TILs may also be used as a biomarker to predict the efficacy of PD-1/PD-L1 inhibitors (67). In NSCLC, an abundance of TILs in primary tumor tissue has been associated with a more favorable 


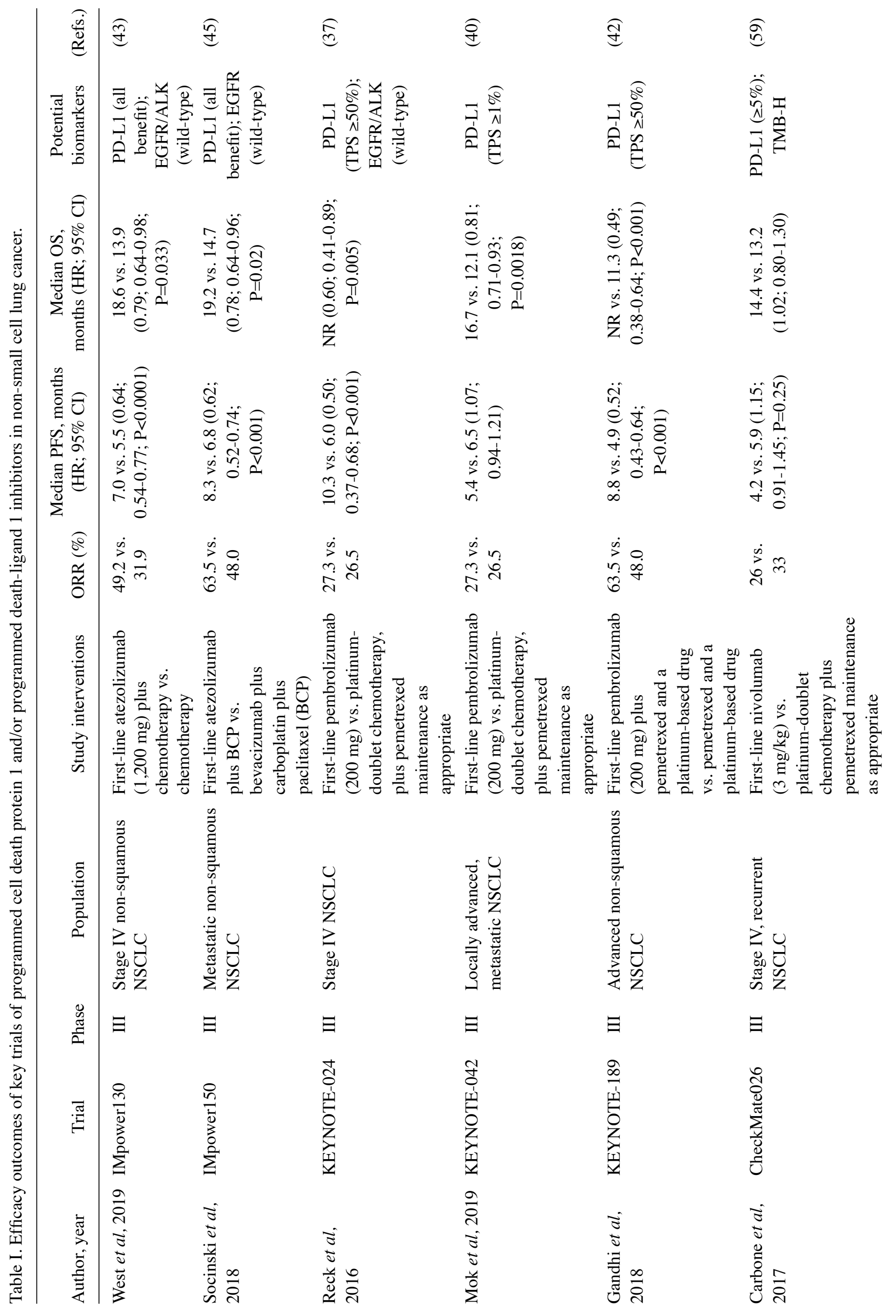




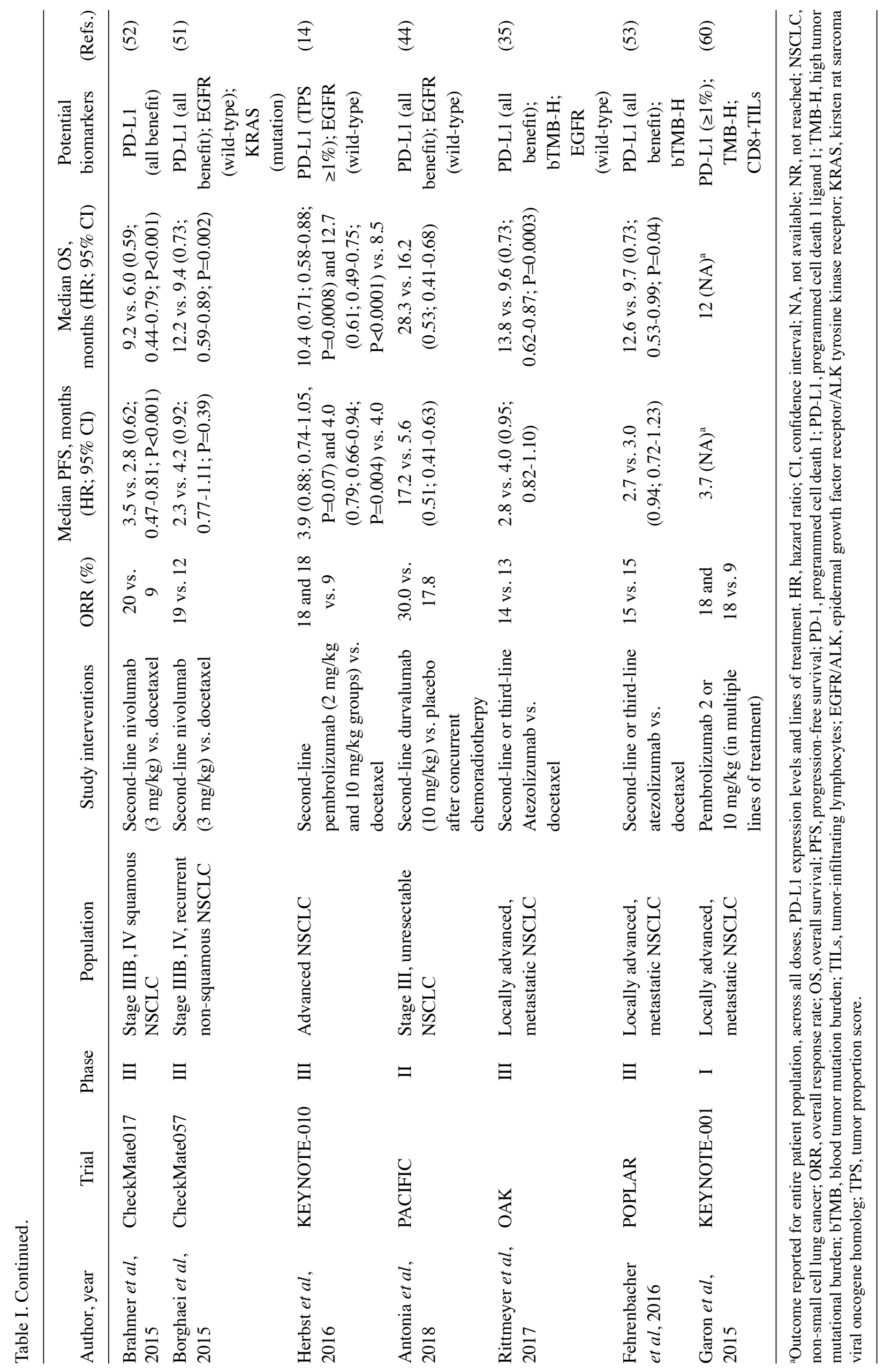




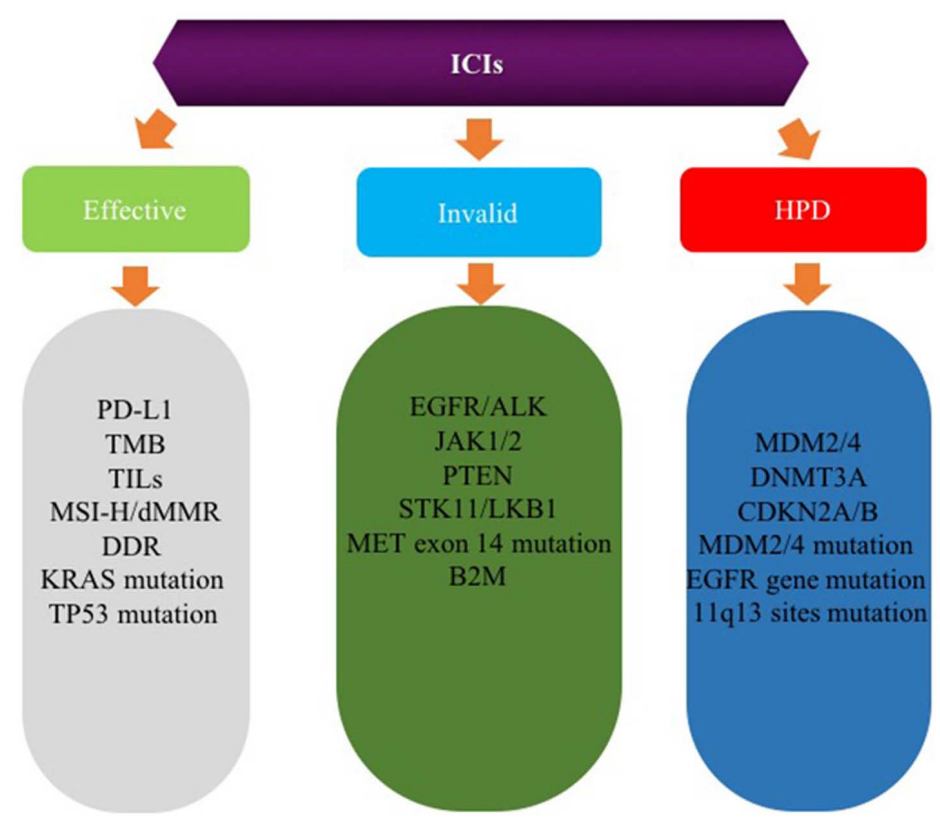

Figure 2. Overview of biomarkers for immune checkpoint inhibition in non-small cell lung cancer. ICIs, immune checkpoint inhibitors; PD-L1, programmed death ligand 1; TMB, tumor mutational burden; TILs, tumor-infiltrating lymphocytes; MSI-H, microsatellite instability, high; dMMR, DNA mismatched repair; DDR, DNA damage repair; KRAS, kirsten rat sarcoma viral oncogene homolog; TP53, tumor protein p53; EGFR/ALK, epidermal growth factor receptor/ALK tyrosine kinase receptor; JAK1/2, Janus kinase 1/2; PTEN, phosphate and tension homology deleted on chromosome ten; STK11, serine/threonine kinase 11; LKB1, Lkb1 kinase; MET, MET proto-oncogene receptor tyrosine kinase; B2M, $\beta$-2-microglobulin; MDM2/4, MDM2/4 proto-oncogene; DNMT3A, DNA methyltransferase $3 \alpha$; CDKN2A/B, cyclin dependent kinase inhibitor 2A/2B.

prognosis (67). TILs, particularly infiltration by $\mathrm{CD} 8^{+} \mathrm{T}$ cells, often indicates a good response to immunotherapy and a favorable prognosis $(68,69)$. It was previously demonstrated that patients with metastatic melanoma with high numbers of $\mathrm{CD}^{+} \mathrm{T}$ cells in tumor tissues and tumor margins are more responsive to immunotherapy compared with conventional cytotoxic chemotherapy (12). The proliferation of $\mathrm{CD}^{+} \mathrm{T}$ cells has been directly associated with the shrinkage of tumors on imaging after ICI treatment (70). In KEYNOTE-001, the number of $\mathrm{CD}^{+} \mathrm{T}$ lymphocytes in the tumor parenchyma and margins of the baseline biopsy specimen of patients with effective pembrolizumab treatment were found to be higher compared with those with disease progression (60).

Recently, Sun et al (71) developed a radiological signature for $\mathrm{CD}^{+} \mathrm{T}$ cells, which was validated using the gene expression signature of $\mathrm{CD}^{+} \mathrm{T}$ cells. The imaging biomarker could estimate the $\mathrm{CD}^{+} \mathrm{T}$ cell count and inferred the clinical outcome of patients treated with immunotherapy.

The immune microenvironment of PD-L1 and TILs is divided into four states as follows (72): I ( $\mathrm{TIL}^{+} / \mathrm{PD}^{-\mathrm{L}^{+}}{ }^{+}$, II (TIL/PD-L1'), III ( TIL $^{+} / \mathrm{PD}-\mathrm{L1}^{-}$) And IV (TIL/PD-L1 ${ }^{+}$). Based on this method, the association between PD-L1 and $\mathrm{CD}^{+}$TIL density in patients with stage III NSCLC receiving concurrent chemoradiotherapy was evaluated (73). The PFS in patients with type I, II, III and IV was 17.6, 13.1, not reached (NR) and 8.6 months $(\mathrm{P}=0.02)$, respectively, and the $\mathrm{OS}$ was $35.3,36.9, \mathrm{NR}$ and 13.9 months $(\mathrm{P}=0.11)$, respectively. The results demonstrate that the PFS and OS are longer in patients with high numbers of CD8 ${ }^{+}$TILs, and suggests that the abundance of TILs may be used as a biomarker for immunotherapy.

Microsatellite instability (MSI)-H/mismatched repairdeficient (MMR). DNA MMR (dMMR) is an important replication error avoidance mechanism that prevents mutation and is essential for maintenance of genetic information, since it repairs polymerase errors during replication and prevents recombination between closely related sequences (74). MSI is a form of genomic instability due to reduced fidelity during the replication of repetitive DNA (74). The highly unstable state of microsatellites is referred to as MSI-H or dMMR, which is easily recognized by the immune system (74).

It was demonstrated that patients with MSI-H/dMMR are more likely to benefit from immunotherapy $(75,76)$. Pembrolizumab has been approved by the FDA for use in MSI-H/dMMR-positive solid tumors that are unresectable or metastatic in patients who receive no other treatments (77). In addition, nivolumab and pembrolizumab were considered as alternative second- or third-line treatments for $\mathrm{dMMR} / \mathrm{MSI}-\mathrm{H}$ metastatic colorectal cancer (mCRC) in the 2017 NCCN guidelines (78). The CheckMate142 study confirmed that mCRC with MSI-H/dMMR treated with nivolumab and pembrolizumab had an increased immune response compared with nivolumab monotherapy (79). Moreover, nivolumab has been approved for mCRC with MSI-H/dMMR following unsuccessful standard chemotherapy (80). Thus, MSI-H/dMMR has emerged as another immunotherapy-related biomarker for screening the subpopulation of patients that are likely to benefit from immunotherapy.

Others. Genes and signaling pathways associated with DNA damage repair (DDR) in tumor cells may lead to genomic instability. A previous study suggested that the mutation status of DDR was correlated with the level of TMB, and that patients with co-mutation may benefit more from immunotherapy (81). A retrospective analysis also found that the PFS and OS of patients with metastatic urothelial carcinoma with DDR 
mutations were significantly improved with anti-PD-1/PD-L1 antibody treatment (82).

KRAS mutations are found in $15-20 \%$ of patients with NSCLC, particularly in smokers with lung adenocarcinoma (83). KRAS mutations are implicated in tumor formation, proliferation, migration, diffusion and angiogenesis (84). A retrospective study demonstrated that patients with KRAS mutations exhibited low expression of PD-L1 and a high somatic mutation load (85), whereas others also suggested that KRAS was positively correlated with PD-L1 expression, while it did not regulate PD-L1 expression (86). Notably, CheckMate-057 confirmed that patients with KRAS mutations benefited more from nivolumab compared with those without KRAS mutations (51). The BIRCH study also reported that patients with advanced NSCLC with KRAS mutations receiving atezolizumab had better outcomes compared with those with wild-type KRAS (87).

It has been described that the mutation rate of TP53 was $39-46 \%$ in adenocarcinomas, $81 \%$ in squamous cell carcinomas and $68 \%$ in large-cell carcinomas (88). Dong et al (89) reported that mutation of TP53 or KRAS increased the expression of PD-L1 and infiltration by $\mathrm{CD}^{+} \mathrm{T}$ cells. DNA polymerase deltacatalytic subunit gene 1 (POLD1), DNA polymerase epsilon catalytic subunit (POLE), Breast cancer susceptibility gene 1 (BRCA1), Breast cancer susceptibility gene 2 (BRCA2), the catalytic subunit of the DNA-activated protein kinase (PRK-DC), DNA ligase 3 (LIG3), RAD17 checkpoint clamp loader component (RAD17), RAD51 paralog C (RAD51C), FA complementation group $\mathrm{F}$ (FANCF), endonuclease non-catalytic subunit of ERCC excision repair 1 (ERCC1) and other rare genetic changes associated with equilibrium and repair of functional proteins in the process of DNA replication also affect the efficacy of immunotherapy. These mutations lead to an increase in the load of non-synonymous mutations and the number of TILs, making patients more sensitive to immunotherapy $(90,91)$. Anti-PD-1 antibodies have been reported to be highly effective in endometrial, bowel and lung cancer patients harboring the POLE mutation (92-94).

Predictors of invalid immunotherapy. Molecular targeted therapy has been found to prolong the OS and PFS of patients with advanced NSCLC; however, it is difficult to effectively treat this type of cancer due to the instability of the driver genes (95). Interactions between the tumor driver gene pathway and the PD-1/PD-L1 pathway have been demonstrated previously $(14,35,37,43-45,51)$. In addition to driver gene mutations, factors in immunotherapy-resistant pathways appear to be involved $(96,97)$. For example, it has been demonstrated that IFN- $\gamma$ is able to recognize the corresponding receptors on tumor cells or APCs (98), and that mutations and deletions of the IFN- $\gamma$ receptor chains, such as Janus kinase (JAK)1 and JAK2, STATs and INF regulatory factor 1 , lead to resistance to ICIs. Moreover, multiple mechanisms may stimulate high expression of PD-L1, including phosphatase and tensin homolog (PTEN) deletion or PI3K/AKT mutation, EGFR mutation, MYC overexpression, CDK5 gene fragmentation and 3'-untranslated region truncation of PD-L1 $(99,100)$. It remains unknown whether the high expression of PD-L1 affects the response to ICIs, but it may indeed lead to a lack of therapeutic response in antitumor immunotherapies by inhibiting the activation of antitumor T cells $(99,100)$.

EGFR and ALK mutation. Based on the findings of KEYNOTE-024, the FDA approved pembrolizumab for initial treatment of NSCLC with high PD-L1 expression $(\geq 50 \%)$ and EGFR/ALK mutation-negative, which accounts for approximately one-third of these cancer types. In the phase II trial of KEYNOTE-001, 64\% (seven out of 11) of patients were positive for EGFR mutations (exons 19 and 21), and 73\% (eight out of 11) of patients exhibited high PD-L1 expression (60). Among patients with NSCLC, the rate of effectiveness of anti-PD-1 treatment was almost zero. In the IMpower150 study, patients with advanced NSCLC with EGFR mutations did not benefit from the combination of PD-L1 and chemotherapy (45). Similar results were reported by phase III of the KEYNOTE-010, CheckMate057 and OAK trials $(14,35,51)$. Multiple clinical trials and retrospective studies have demonstrated that the ORR of patients with ALK mutations treated with anti-PD1/PD-L1 inhibitors is lower compared with that of patients with the wild-type $(14,35,45,51,69)$. The reasons for the poor therapeutic effect of anti-PD-1/PD-L1 agents in patients with EGFR/ALK mutation is that these patients may have a lower proportion of $\mathrm{PD}-\mathrm{L1}^{+} / \mathrm{CD}^{+}$cells, as well as having a non-inflammatory phenotype and weak immunogenicity (101).

Phase III clinical trials have confirmed that NSCLC with EGFR mutations exhibited a lower response to ICIs; however, ICIs were found to be effective against some patients with NSCLC with EGFR mutations (98-101). Hastings et al (102) found that EGFR mutations in different alleles may affect the response to immunosuppressive agents. In addition, smoking may be associated with the opposite result. Another study demonstrated that the effectiveness of anti-PD-1 therapy, regardless of EGFR mutations, was $>20 \%$ in patients with NSCLC who were smokers (103). The latest ATLANTIC trial confirmed that patients with EGFR mutations and PD-L1 expression $\geq 25 \%$ may benefit from durvalumab (104). The efficacy of durvalumab was the lowest in patients with NSCLC with low expression of PD-L1 and $\mathrm{EGFR}^{+} / \mathrm{ALK}^{+}$[only one of 128 patients $(4 \%)$ reached OR].

Recently, Su et al (105) published a retrospective study on the association between the expression of PD-L1 in patients with NSCLC with EGFR mutations and the therapeutic effects of EGFR-TKI. Compared with the low or no expression of PD-L1, high expression of PD-L1 was associated with a worse ORR (35.7 vs. 63.2 vs. $67.3 \%$, respectively; $\mathrm{P}=0.002$ ) and $\mathrm{PFS}$ (3.8 vs. 6.0 vs. 9.5 months, respectively; $\mathrm{P}<0.001$ ). In addition, PD-L1 expression and the proportion of PD-L1 ${ }^{+}$and $\mathrm{CD}^{+}$ $\mathrm{T}$ cells in patients with primary resistance to EGFR-TKIs were higher compared with those with acquired EGFR-TKI resistance. In conclusion, the higher the expression of PD-L1 in patients with EGFR mutations, the poorer the efficacy of EGFR-TKIs. Therefore, patients with primary resistance to EGFR-TKIs might benefit from PD-1 immunotherapy.

JAK1/2 mutations. Upon tumor antigen recognition, $\mathrm{T}$ cells produce IFN- $\gamma$, which leads to the expression of IFN-stimulated genes through the IFN- $\gamma$ receptors, including JAK1 and JAK2, and also activates STAT signaling (106). JAK1/2 mutations have 
been found to be associated with loss of PD-L1 expression upon IFN- $\gamma$ exposure mediated by disabling the receptor signaling pathway $(106,107)$. Shin et al (107) reported two cases with JAK1/2 loss-of-function mutations and lack of reactive PD-L1 expression. Therefore, patients with JAK1/2 mutations may not be not suitable candidates for PD-1 blockade therapy (108).

PTEN deletion. As a tumor suppressor gene, PTEN serves a regulatory role in some of the key cell processes in tumor proliferation. The deletion of PTEN increases the activity of the PI3K-AKT signaling pathway in various types of tumors $(109,110)$. In a study on melanoma, PTEN deletion decreased the effectiveness of anti-PD-1 inhibitors through upregulation of the expression of tumor immunosuppressive factors, suggesting that the absence of PTEN is associated with resistance to ICIs $(96,111)$. The melanoma database of The Cancer Genome Atlas (http://cancergenome.nih.gov) shows that the deletion of PTEN is significantly correlated with the downregulation of IFN- $\gamma$ and the infiltration of granzyme $\mathrm{B}$ and $\mathrm{CD} 8^{+} \mathrm{T}$ lymphocytes. In addition, it shows that the deletion and mutation of the PTEN gene occurs more frequently in tumors without $\mathrm{T}$ cell inflammatory infiltration (112). However, the role of the PTEN gene in immunotherapy of lung cancer remains unclear and requires further investigation.

Serine/threonine kinase (STK)11 deletion and LKB1 kinase mutation. Immunotherapy may not be effective in patients with a STK11 gene deletion due to the lower PD-L1 expression in this population (113). Dong et al (89) demonstrated that patients with co-mutation of KRAS/TP53 had the greatest clinical benefit (ORR 30\%) compared with those with co-mutation of KRAS/STK11, suggesting that STK11 deletion may be one of the main reasons for primary resistance to ICIs in patients with KRAS mutations in lung adenocarcinoma. Skoulidis et al (114) reported that patients with KRAS-mutated lung adenocarcinoma (7.4 vs. 35.7 vs. $28.6 \%$; $<<0.001)$ and those treated with nivolumab ( 0 vs. 57.1 vs. $18.2 \% ; \mathrm{P}=0.047$ ) differed significantly in ORR. Therefore, STK11/LKB1 mutation may be the main driver of primary resistance to PD-1 inhibitors in KRAS-mutated lung adenocarcinoma.

Others. The incidence of MET proto-oncogene receptor tyrosine kinase $(M E T)$ exon 14 mutations in patients with NSCLC is $2-4 \%$. Patients usually have a smoking history and high expression of PD-L1, inducing more prominent tumor immune cell infiltration. In contrast, low levels of TMB have been found to be associated with worse response to immunotherapy (115).

$\beta$-2-microglobulin (B2M) was found to be inactivated in $\sim 5 \%$ of all primary NSCLCs and SCLCs, and the presence of mutations was strongly correlated with the loss of the human leukocyte antigen-I complex, which strengthens the specificity of cytotoxic T lymphocyte activation against tumor cells (116). $B 2 M$ loss-of-function mutations are also involved in the acquisition of resistance to ICI treatment, as was first described in patients with melanoma (117) and later in a patient with NSCLC who progressed to anti-PD-1 (118).

Predictors of 'toxic' immunotherapy. HPD, also known as the 'toxic' response, may occur in targeted therapy and chemotherapy; however, the incidence of HPD after immunotherapy is significantly increased to $>29 \%$, including $10-16 \%$ in patients with NSCLC compared with those that did not receive immunotherapy (119). Patients with HPD have a poor overall prognosis, with an OS of only 3-4 months (120). In early 2017, HPD occurred in $~ 9 \%$ of patients treated with ICIs and $19 \%$ of the patients were aged $>65$ years (121). In addition, immunotherapy-induced HPD was not correlated with tumor load, tumor type, number of treatment lines or PD-L1 expression level, but was associated with advanced age ( $>65$ years) and poor OS (121). HPD is principally observed with PD-1/PD-L1 inhibitors; however, there is no significant difference between PD-1 inhibitors and PD-L1 inhibitors in the occurrence of HPD (121). In the clinical setting, patients with lung cancer with driver gene mutations have higher rates of HPD. A retrospective study found that $>500$ patients with eight common lung cancer gene mutations had a high incidence of HPD in all the mutations after using PD-1/PD-L1 alone. Among these mutations, the incidence of EGFR, ALK and RET mutations were 44.8, 45.5 and $43.8 \%$, respectively (122). In regard to the factors and mechanisms of HPD, studies have demonstrated that certain clinical characteristics are associated with HPD, such as age $>65$ years, number of baseline metastatic sites $>2$ or local recurrence, although these characteristics have inconsistent results in different studies and are not sufficient as predictors $(13,119,123,124)$. A review summarized the five biological mechanisms by which PD-1/PD-L1 inhibitors may cause HPD; four of those formed an immunosuppressive microenvironment to facilitate the immune escape of tumor cells and indirectly accelerate tumor growth, while one directly promoted tumor cell proliferation through the activation of oncogenes (125). Gene variation has been associated with HPD; however, basic experiments and further investigation, including studies about mouse double minute $(M D M) 2 / 4$ amplification, DNA methyltransferase $3 \alpha$ (DNMT3A) mutation and cyclin dependent kinase inhibitor $2 \mathrm{~A} / 2 \mathrm{~B}(C D K N 2 A / B)$ deletion, are required.

MDM2/4 amplification. MDM2 is a critical negative regulator of p53, and plays a key role in controlling its transcriptional activity, protein stability and nuclear localization (126). MDM2 expression is upregulated in numerous cancer types, resulting in a loss of p53-dependent functions, apoptosis and cell cycle arrest (126). Previous studies have demonstrated that the MDM2 protein has low expression levels in normal tissues, and that amplification of the MDM2 gene may lead to tumorigenesis (126). Kato et al (121) reported that $67 \%$ (four out of six) patients with $M D M 2 / 4$ gene amplification-induced HPD and that the clinical symptoms of the other two patients rapidly deteriorated, suggesting that $M D M 2 / 4$ gene amplification may be associated with HPD. In another article published in 2018, Kato et al (127) further explored the amplification status of MDM2 after immunotherapy in various cancer types. MDM2 amplification accounted for 3.5\% (3,650 cases) of the tumors, among which $99.0 \%$ (3,613 cases) had genomic co-mutations, and the most common co-mutated genes were $C D K 4$ (43.6\%), fibroblast growth factor receptor substrate 2 (40.8\%), TP53 (20.1\%) and $C D K N 2 A(18.2 \%)$. Various pathways, including those associated with tyrosine kinase $(37.9 \% ; 1,385 / 3,650)$, PI3K signaling $(25.4 \%$; 926/3,650), TP53 $(24.9 \% ; 910 / 3,650)$ and MAPK signaling $(23.6 \% ; 863 / 3,650)$ were involved. In 
addition, $M D M 2$ amplifications were less frequently associated with TMB-H compared with the MDM2 wild-type population (2.9 vs. $6.5 \%$, respectively; $\mathrm{P}<0.001$ ).

DNMT3A mutation and CDKN2A/B deletion. Kato et al (121) demonstrated that DNMT3A gene mutation was closely associated with immunotherapy-related HPD. It was further confirmed that $C D K N 2 A / B$ deletion and $M D M 2$ mutation were strongly correlated with HPD after immunotherapy at the 2019 American Society of Clinical Oncology Meeting (abstract no. e20628) (128). Tumor growth was $>50 \%$ after treatment with pembrolizumab in advanced NSCLC. MDM2 gene amplification was observed in all patients, and deletion of $C D K N 2 A / B$ was reported in four patients. Moreover, none of the patients with non-HPD had amplification of the MDM2 gene or protein.

Others. Kato et al (121) revealed that MDM2/4 (66\%), EGFR (50\%) and 11q13 mutations (43\%) were associated with HPD. However, their role as expected biomarkers for HPD must be further validated in a larger cohort.

\section{Conclusions and future perspectives}

Immunotherapy for NSCLC has recently evolved into a new standard treatment modality primarily through PD-1 and PD-L1 inhibitors. However, patient selection is currently at the discretion of the treating physician. The predictors mentioned in the present review are based on the latest research results, and are innovatively classified into three categories: Effective, invalid and 'toxic'. All the biomarkers aforementioned may be incorporated into the prognostic bio-score systems and decision-making algorithms to better guide the application of clinical immunotherapy.

Despite efforts focusing on immunotherapy in NSCLC, a number of issues remain to be addressed in future studies. Currently available evidence indicates that PD-L1, TMB and MSI-H/dMMR have been acknowledged for screening the population in whom immunotherapy is effective of immune drugs, thus it is crucial to improve drug efficiency and reduce the incidence of adverse reactions. However, these markers allPD-L1, TMB and MSI-H/dMMR have certain drawbacks, for example some of the predictors have not been identified due to the limited clinical validation sample size and contradictory research results, which requires further confirmation by prospective studies with larger sample size. In addition, biomarkers and their mechanisms of action remain under investigation, therefore the role of gene mutations in immunotherapy of lung cancer requires further clinical research and experiments to verify in the context of precision medicine. Scoring tools based on blood indicators or characteristic expression of tumor gene profiles, including LIPI, TIDE and IMPRES scores, have not been widely used due to their respective drawbacks (129-131), and an immune prognosis assessment scale must be developed by combining various predicted molecules. Positron emission tomography combined with $\mathrm{CT}$, dynamic contrast-enhanced $\mathrm{CT}$ and diffusion-weighted magnetic resonance imaging have demonstrated promising results for diagnosing and staging patients with lung cancer (132), and improvement of the evaluation criteria for immunotherapy and the risk of HPD are expected to make these predictions more precise $(133,134)$.
Immunotherapy has long-lasting therapeutic activity and appears to hold promise for patients with NSCLC (135). Efforts must be focused on identifying patients who may benefit from this type of treatment through biomarkers, and on effectively controlling adverse reactions.

\section{Acknowledgements}

Not applicable.

\section{Funding}

This work was supported in part by the General Project (grant nos. 81800074 and 81901454) from the National Natural Science Foundation of China and the Youth Foundation Project of Zhejiang Province of China (grant no. LQ18H010002).

\section{Availability of data and materials}

Not applicable.

\section{Authors' contributions}

YH and XCW conceived and designed the study. LLW, YH and SCW wrote the manuscript. XCW and JLS revised the article for important intellectual content. All authors read and approved the final manuscript.

\section{Ethics approval and consent to participate}

Not applicable.

\section{Patient consent for publication}

Not applicable.

\section{Competing interests}

The authors declare that they have no competing interests.

\section{References}

1. Siegel RL, Miller KD and Jemal A: Cancer statistics, 2019. CA Cancer J Clin 69: 7-34, 2019.

2. Osmani L, Askin F, Gabrielson E and Li QK: Current WHO guidelines and the critical role of immunohistochemical markers in the subclassification of non-small cell lung carcinoma (NSCLC): Moving from targeted therapy to immunotherapy. Semin Cancer Biol 52: 103-109, 2018.

3. Gettinger S, Horn L, Jackman D, Spigel D, Antonia S, Hellmann M, Powderly J, Heist R, Sequist LV, Smith DC, et al: Five-year follow-up of nivolumab in previously treated advanced non-small-cell lung cancer: Results from the CA209-003 study. J Clin Oncol 36: 1675-1684, 2018.

4. Kelly K, Crowley J, Bunn PA Jr, Presant CA, Grevstad PK, Moinpour CM, Ramsey SD, Wozniak AJ, Weiss GR, Moore DF, et al: Randomized phase III trial of paclitaxel plus carboplatin versus vinorelbine plus cisplatin in the treatment of patients with advanced non-small-cell lung cancer: A Southwest oncology group trial. J Clin Oncol 19: 3210-3218, 2001.

5. Schiller JH, Harrington D, Belani CP, Langer C, Sandler A, Krook J, Zhu J and Johnson DH; Eastern Cooperative Oncology Group: Comparison of four chemotherapy regimens for advanced non-small-cell lung cancer. N Engl J Med 346: 92-98, 2002.

6. McNutt M: Cancer immunotherapy. Science 342: 1417, 2013. 
7. Pardoll DM: The blockade of immune checkpoints in cancer immunotherapy. Nat Rev Cancer 12: 252-264, 2012.

8. Zago G, Muller M, van den Heuvel M and Baas P: New targeted treatments for non-small-cell lung cancer-role of nivolumab. Biologics 10: 103-117, 2016

9. Camidge DR, Doebele RC and Kerr KM: Comparing and contrasting predictive biomarkers for immunotherapy and targeted therapy of NSCLC. Nat Rev Clin Oncol 16: 341-355, 2019.

10. Suresh K, Naidoo J, Lin CT and Danoff S: Immune checkpoint immunotherapy for non-small cell lung cancer: Benefits and pulmonary toxicities. Chest 154: 1416-1423, 2018.

11. Santini FC, Rizvi H, Plodkowski AJ, Ni A, Lacouture ME, Gambarin-Gelwan M, Wilkins O, Panora E, Halpenny DF, Long NM, et al: Safety and efficacy of re-treating with immunotherapy after immune-related adverse events in patients with NSCLC. Cancer Immunol Res 6: 1093-1099, 2018

12. Di Giacomo AM, Danielli R, Guidoboni M, Calabrò L, Carlucci D, Miracco C, Volterrani L, Mazzei MA, Biagioli M, Altomonte $\mathrm{M}$ and Maio $\mathrm{M}$ : Therapeutic efficacy of ipilimumab, an anti-CTLA-4 monoclonal antibody, in patients with metastatic melanoma unresponsive to prior systemic treatments: Clinical and immunological evidence from three patient cases. Cancer Immunol Immunother 58: 1297-1306, 2009.

13. Champiat S, Dercle L, Ammari S, Massard C, Hollebecque A Postel-Vinay S, Chaput N, Eggermont A, Marabelle A, Soria JC and Ferté C: Hyperprogressive disease is a new pattern of progression in cancer patients treated by anti-PD-1/PD-L1. Clin Cancer Res 23: 1920-1928, 2017.

14. Herbst RS, Baas P, Kim DW, Felip E, Pérez-Gracia JL, Han JY, Molina J, Kim JH, Arvis CD, Ahn MJ, et al: Pembrolizumab versus docetaxel for previously treated,PD-L1-positive, advanced non-small-cell lung cancer (KEYNOTE-010): A randomised controlled trial. Lancet 387: 1540-1550, 2016.

15. Xia L, Liu Y and Wang Y: PD-1/PD-L1 blockade therapy in advanced non-small-cell lung cancer: Current status and future directions. Oncologist 24 (Suppl 1): S31-S41, 2019.

16. Yang Y: Cancer immunotherapy: Harnessing the immune system to battle cancer. J Clin Invest 125: 3335-3337, 2015.

17. Wang W, Liu J, He Y and McLeod HL: Prospect for immune checkpoint blockade: Dynamic and comprehensive monitorings pave the way. Pharmacogenomics 18: 1299-1304, 2017.

18. Almand B and Carbone DP: Biological considerations in lung cancer. Cancer Treat Res 105: 1-30, 2001.

19. Assi HI, Kamphorst AO, Moukalled NM and Ramalingam SS Immune checkpoint inhibitors in advanced non-small cell lung cancer. Cancer 124: 248-261, 2018.

20. Chen L and Flies DB: Molecular mechanisms of $\mathrm{T}$ cell co-stimulation and co-inhibition. Nat Rev Immunol 13: 227-242, 2013.

21. Schildberg FA, Klein SR, Freeman GJ and Sharpe AH: Coinhibitory pathways in the B7-CD28 ligand-receptor family. Immunity 44: 955-972, 2016.

22. Rowshanravan B, Halliday N and Sansom DM: CTLA-4: A moving target in immunotherapy. Blood 131: 58-67, 2018.

23. Arce Vargas F, Furness AJS, Litchfield K, Joshi K, Rosenthal R, Ghorani E, Solomon I, Lesko MH, Ruef N, Roddie $\mathrm{C}$, et al: $\mathrm{Fc}$ effector function contributes to the activity of human anti-CTLA-4 antibodies. Cancer Cell 33: 649-663.e4, 2018.

24. Walker LS: Treg and CTLA-4: Two intertwining pathways to immune tolerance. J Autoimmun 45: 49-57, 2013.

25. Corrales L, Scilla K, Caglevic C, Miller K, Oliveira J and Rolfo C: Immunotherapy in lung cancer: A new age in cancer treatment. Adv Exp Med Biol 995: 65-95, 2018.

26. Govindan R, Szczesna A, Ahn MJ, Schneider CP, Gonzalez Mella PF, Barlesi F, Han B, Ganea DE, Von Pawel J, Vladimirov V, et al: Phase III trial of ipilimumab combined with paclitaxel and carboplatin in advanced squamous non-small-cell lung cancer. J Clin Oncol 35: 3449-3457, 2017.

27. Boussiotis VA, Chatterjee P and Li L: Biochemical signaling of PD-1 on T cells and its functional implications. Cancer J 20 : 265-271, 2014

28. Wang X, Teng F, Kong L and Yu J: PD-L1 expression in human cancers and its association with clinical outcomes. Onco Targets Ther 9: 5023-5039, 2016.

29. Machicote A, Belén S, Baz P, Billordo LA and Fainboim L: Human CD8+HLA-DR+ regulatory T cells, similarly to classical CD4+Foxp3+ cells, suppress immune responses via PD-1/PD-L1 axis. Front Immunol 9: 2788, 2018.
30. Ventriglia J, Paciolla I, Pisano C, Cecere SC, Di Napoli M, Tambaro R, Califano D, Losito S, Scognamiglio G, Setola SV, et al: Immunotherapy in ovarian, endometrial and cervical cancer: State of the art and future perspectives. Cancer Treat Rev 59: 109-116, 2017.

31. Yahata T, Mizoguchi M, Kimura A, Orimo T, Toujima S, Kuninaka Y, Nosaka M, Ishida Y, Sasaki I, Fukuda-Ohta Y, et al: Programmed cell death ligand 1 disruption by clustered regularly interspaced short palindromic repeats/Cas9-genome editing promotes antitumor immunity and suppresses ovarian cancer progression. Cancer Sci 110: 1279-1292, 2019.

32. Boussiotis VA: Molecular and biochemical aspects of the PD-1 checkpoint pathway. N Engl J Med 375: 1767-1778, 2016.

33. Gajewski TF, Schreiber H and Fu YX: Innate and adaptive immune cells in the tumor microenvironment. Nat Immunol 14 1014-1022, 2013

34. Spranger S, Spaapen RM, Zha Y, Williams J, Meng Y, Ha TT and Gajewski TF: Up-regulation of PD-L1, IDO, and T(regs) in the melanoma tumor microenvironment is driven by CD8(+) T cells Sci Transl Med 5: 200ra116, 2013.

35. Rittmeyer A, Barlesi F, Waterkamp D, Park K, Ciardiello F, von Pawel J, Gadgeel SM, Hida T, Kowalski DM, Dols MC, et al: Atezolizumab versus docetaxel in patients with previously treated non-small-cell lung cancer (OAK): A phase 3, open-label, multicentre randomised controlled trial. Lancet 389: 255-265, 2017.

36. Vokes EE, Ready N, Felip E, Horn L, Burgio MA, Antonia SJ, Arén Frontera O, Gettinger S, Holgado E, Spigel D, et al: Nivolumab versus docetaxel in previously treated advanced non-small-cell lung cancer (CheckMate 017 and CheckMate 057): 3-Year update and outcomes in patients with liver metastases. Ann Oncol 29: 959-965, 2018.

37. Reck M, Rodriguez-Abreu D, Robinson AG, Hui R, Csőszi T, Fülöp A, Gottfried M, Peled N, Tafreshi A, Cuffe S, et al: Pembrolizumab versus chemotherapy for PD-L1-positive non-small-cell lung cancer. N Engl J Med 375: 1823-1833, 2016.

38. Nosaki K, Saka H, Hosomi Y, Baas P, de Castro G Jr, Reck M, Wu YL, Brahmer JR, Felip E, Sawada T, et al: Safety and efficacy of pembrolizumab monotherapy in elderly patients with PD-L1-positive advanced non-small-cell lung cancer: Pooled analysis from the KEYNOTE-010, KEYNOTE-024, and KEYNOTE-042 studies. Lung Cancer 135: 188-195, 2019.

39. Lopes G, Wu YL, Kudaba I, Kowalski D, Cho BC, Bondarenko I, Kubota K, Lubiniecki GM, Zhang J, Kush DA and Mok T: Pembrolizumab (pembro) versus platinum-based chemotherapy (chemo) as first-line therapy for advanced/metastatic NSCLC with a PD-L1 tumor proportion score (TPS) $>=1 \%$ : Open-label, phase 3 KEYNOTE-042 study. J Clin Oncol 36: (18 Suppl): LBA4-LBA4, 2018.

40. Mok TSK, Wu YL, Kudaba I, Kowalsk DM, Cho BC, Turna HZ, de Castro G Jr, Srimuninnimit V, Laktionov KK, Bondarenko I, et al: Final analysis of the phase III KEYNOTE-042 study: Pembrolizumab (Pembro) versus platinum-based chemotherapy (Chemo) as first-line therapy for patients (Pts) with PD-L1-positive locally advanced/metastatic NSCLC. Ann Oncol 30 (Suppl 2): ii38-ii68, 2019.

41. Oezkan F, He K, Owen D, Pietrzak M, Cho Jh, Kitzler R, Pearson R, Rusch V, Chaft J, Suh R, et al: OA13.07 Neoadjuvant atezolizumab in resectable NSCLC patients: Immunophenotyping results from the interim analysis of the multicenter trial LCMC3 J Thorac Oncol 14 (10 Suppl): S242-S243, 2019.

42. Gandhi L, Rodriguez-Abreu D, Gadgeel S, Esteban E, Felip E, De Angelis F, Domine M, Clingan P, Hochmair MJ, Powell SF, et al: Pembrolizumab plus chemotherapy in metastatic non-small-cell lung cancer. N Engl J Med 378: 2078-2092, 2018

43. West H, McCleod M, Hussein M, Morabito A, Rittmeyer A, Conter HJ, Kopp HG, Daniel D, McCune S, Mekhail T, et al: Atezolizumab in combination with carboplatin plus nab-paclitaxel chemotherapy compared with chemotherapy alone as first-line treatment for metastatic non-squamous non-small-cell lung cancer (IMpower130): A multicentre, randomised, open-label, phase 3 trial. Lancet Oncol 20: 924-937, 2019.

44. Antonia SJ, Villegas A, Daniel D, Vicente D, Murakami S, Hui R, Kurata T, Chiappori A, Lee KH, de Wit M, et al: Overall survival with durvalumab after chemoradiotherapy in stage III NSCLC. N Engl J Med 379: 2342-2350, 2018.

45. Socinski MA, Jotte RM, Cappuzzo F, Orlandi F, Stroyakovskiy D, Nogami N, Rodríguez-Abreu D, Moro-Sibilot D, Thomas CA, Barlesi F, et al: Atezolizumab for first-line treatment of metastatic nonsquamous NSCLC. N Engl J Med 378: 2288-2301, 2018. 
46. Buchbinder EI and Desai A: CTLA-4 and PD-1 pathways: Similarities, differences, and implications of their inhibition. Am J Clin Oncol 39: 98-106, 2016.

47. Wei SC, Levine JH, Cogdill AP, Zhao Y, Anang NAS, Andrews MC, Sharma P, Wang J, Wargo JA, Pe'er D and Allison JP: Distinct cellular mechanisms underlie anti-CTLA-4 and anti-PD-1 checkpoint blockade. Cell 170: 1120-1133.e17, 2017.

48. Curran MA, Montalvo W, Yagita H and Allison JP: PD-1 and CTLA-4 combination blockade expands infiltrating T cells and reduces regulatory $\mathrm{T}$ and myeloid cells within B16 melanoma tumors. Proc Natl Acad Sci USA 107: 4275-4280, 2010.

49. Das R, Verma R, Sznol M, Boddupalli CS, Gettinger SN Kluger H, Callahan M, Wolchok JD, Halaban R, Dhodapkar MV and Dhodapkar KM: Combination therapy with anti-CTLA-4 and anti-PD-1 leads to distinct immunologic changes in vivo. J Immunol 194: 950-959, 2015.

50. Reck M, Schenker M, Lee KH, Provencio M, Nishio M, Lesniewski-Kmak K, Sangha R, Ahmed S, Raimbourg J, Feeney K, et al: Nivolumab plus ipilimumab versus chemotherapy as first-line treatment in advanced non-small-cell lung cancer with high tumour mutational burden: Patient-reported outcomes results from the randomised, open-label, phase III CheckMate 227 trial. Eur J Cancer 116: 137-147, 2019.

51. Borghaei H,Paz-Ares L, Horn L, Spigel DR, Steins M, Ready NE, Chow LQ, Vokes EE, Felip E, Holgado E, et al: Nivolumab versus docetaxel in advanced nonsquamous non-small-cell lung cancer. N Engl J Med 373: 1627-1639, 2015.

52. Brahmer J, Reckamp KL, Baas P, Crinò L, Eberhardt WE, Poddubskaya E, Antonia S, Pluzanski A, Vokes EE, Holgado E, et al: Nivolumab versus docetaxel in advanced squamous-cell non-small-cell lung cancer. New Engl J Med 373: 123-135, 2015.

53. Fehrenbacher L, Spira A, Ballinger M, Kowanetz M, Vansteenkiste J, Mazieres J, Park K, Smith D, Artal-Cortes A, Lewanski C, et al: Atezolizumab versus docetaxel for patients with previously treated non-small-cell lung cancer (POPLAR) A multicentre, open-label, phase 2 randomised controlled trial. Lancet 387: 1837-1846, 2016

54. Yu Y, Zeng D, Ou Q, Liu S, Li A, Chen Y, Lin D, Gao Q, Zhou H Liao $\mathrm{W}$ and Yao $\mathrm{H}$ : Association of survival and immune-related biomarkers with immunotherapy in patients with non-small cell lung cancer: A meta-analysis and individual patient-level analysis. JAMA Netw Open 2: e196879, 2019.

55. Chan TA, Yarchoan M, Jaffee E, Swanton C, Quezada SA, Stenzinger A and Peters S: Development of tumor mutation burden as an immunotherapy biomarker: Utility for the oncology clinic. Ann Oncol 30: 44-56, 2019.

56. Salmaninejad A, Valilou SF, Shabgah AG, Aslani S Alimardani M, Pasdar A and Sahebkar A: PD-1/PD-L1 pathway: Basic biology and role in cancer immunotherapy. J Cell Physiol 234: 16824-16837, 2019.

57. Patel SP and Kurzrock R: PD-L1 expression as a predictive biomarker in cancer immunotherapy. Mol Cancer Ther 14: 847-856, 2015

58. Gibney GT, Weiner LM and Atkins MB: Predictive biomarkers for checkpoint inhibitor-based immunotherapy. Lancet Oncol 17: e542-e551, 2016.

59. Carbone DP, Reck M, Paz-Ares L, Creelan B, Horn L, Steins M, Felip E, van den Heuvel MM, Ciuleanu TE, Badin F, et al: First-line nivolumab in stage IV or recurrent non-small-cell lung cancer. New Engl J Med 376: 2415-2426, 2017.

60. Garon EB, Rizvi NA, Hui RN, Leighl N, Balmanoukian AS Eder JP, Patnaik A, Aggarwal C, Gubens M, Horn L, et al Pembrolizumab for the treatment of non-small-cell lung cancer. New Engl J Med 372: 2018-2028, 2015.

61. Fumet JD, Truntzer C, Yarchoan M and Ghiringhelli F: Tumour mutational burden as a biomarker for immunotherapy: Current data and emerging concepts. Eur J Cancer 131: 40-50, 2020.

62. Johnson DB, Frampton GM, Rioth MJ, Yusko E, Xu Y, Guo X, Ennis RC, Fabrizio D, Chalmers ZR, Greenbowe J, et al: Targeted next generation sequencing identifies markers of response to PD-1 blockade. Cancer Immunol Res 4: 959-967, 2016.

63. Yarchoan M, Hopkins A and Jaffee EM: Tumor mutational burden and response rate to PD-1 inhibition. N Engl J Med 377: 2500-2501, 2017

64. Hellmann MD, Ciuleanu TE, Pluzanski A, Lee JS, Otterson GA, Audigier-Valette C, Minenza E, Linardou H, Burgers S, Salman P, et al: Nivolumab plus ipilimumab in lung cancer with a high tumor mutational burden. N Engl J Med 378: 2093-2104, 2018
65. Bylicki O, Barazzutti H, Paleiron N, Margery J, Assié JB and Chouaid C: First-line treatment of non-small-cell lung cancer (NSCLC) with immune checkpoint inhibitors. BioDrugs 33: 159-171, 2019.

66. Rizvi H, Sanchez-Vega F, La K, Chatila W, Jonsson P, Halpenny D, Plodkowski A, Long N, Sauter JL, Rekhtman N, et al: Molecular determinants of response to anti-programmed cell death (PD)-1 and anti-programmed death-ligand 1 (PD-L1) blockade in patients with non-small-cell lung cancer profiled with targeted next-generation sequencing. J Clin Oncol 36: 633-641, 2018.

67. Zeng DQ, Yu YF, Ou QY, Li XY, Zhong RZ, Xie CM and $\mathrm{Hu}$ QG: Prognostic and predictive value of tumor-infiltrating lymphocytes for clinical therapeutic research in patients with non-small cell lung cancer. Oncotarget 7: 13765-13781, 2016.

68. Geng Y, Shao Y, He W, Hu W, Xu Y, Chen J, Wu C and Jiang J: prognostic role of tumor-infiltrating lymphocytes in lung cancer: A meta-analysis. Cell Physiol Biochem 37: 1560-1571, 2015.

69. Dong ZY, Wu SP, Liao RQ, Huang SM and Wu YL: Potential biomarker for checkpoint blockade immunotherapy and treatment strategy. Tumour Biol 37: 4251-4261, 2016.

70. Tumeh PC, Harview CL, Yearley JH, Shintaku IP, Taylor EJ, Robert L, Chmielowski B, Spasic M, Henry G, Ciobanu V, et al: PD-1 blockade induces responses by inhibiting adaptive immune resistance. Nature 515: 568-571, 2014

71. Sun R, Limkin EJ, Vakalopoulou M, Dercle L, Champiat S, Han SR, Verlingue L, Brandao D, Lancia A, Ammari S, et al: A radiomics approach to assess tumour-infiltrating CD8 cells and response to anti-PD-1 or anti-PD-L1 immunotherapy: An imaging biomarker, retrospective multicohort study. Lancet Oncol 19: 1180-1191, 2018.

72. Teng MW, Ngiow SF, Ribas A and Smyth MJ: Classifying cancers based on T-cell infiltration and PD-L1. Cancer Res 75: 2139-2145, 2015.

73. Tokito T, Azuma K, Kawahara A, Ishii H, Yamada K, Matsuo N, Kinoshita T, Mizukami N, Ono H, Kage M and Hoshino T: Predictive relevance of PD-L1 expression combined with CD8+ TIL density in stage III non-small cell lung cancer patients receiving concurrent chemoradiotherapy. Eur J Cancer 55: 7-14, 2016.

74. Baretti M and Le DT: DNA mismatch repair in cancer. Pharmacol Ther 189: 45-62, 2018

75. Nebot-Bral L, Coutzac C, Kannouche PL and Chaput N: Why is immunotherapy effective (or not) in patients with MSI/MMRD tumors? Bull Cancer 106: 105-113, 2019.

76. Quiroga D, Lyerly HK and Morse MA: Deficient mismatch repair and the role of immunotherapy in metastatic colorectal cancer. Curr Treat Options Oncol 17: 41, 2016.

77. Le DT, Kim TW, Van Cutsem E, Geva R, Jäger D, Hara H, Burge M, O'Neil B, Kavan P, Yoshino T, et al: Phase II open-label study of pembrolizumab in treatment-refractory, microsatellite instability-high/mismatch repair-deficient metastatic colorectal cancer: KEYNOTE-164. J Clin Oncol 38: 11-19, 2020.

78. Faivre JC, Adam V, Block V, Metzger M, Salleron J and Dauchy S: Clinical practice guidelines of the French association for supportive care in cancer and the French society for psycho-oncology: Refusal of treatment by adults afflicted with cancer. Support Care Cancer 25: 3425-3435, 2017.

79. Overman MJ, McDermott R, Leach JL, Lonardi S, Lenz HJ, Morse MA,Desai J,Hill A, Axelson M, Moss RA, et al: Nivolumab in patients with metastatic DNA mismatch repair-deficient or microsatellite instability-high colorectal cancer (CheckMate 142): An open-label, multicentre, phase 2 study. Lancet Oncol 18: 1182-1191, 2017.

80. Morse MA, Overman MJ, Hartman L, Khoukaz T, Brutcher E, Lenz HJ, Atasoy A, Shangguan T, Zhao H and El-Rayes B: Safety of nivolumab plus low-dose ipilimumab in previously treated microsatellite instability-high/mismatch repair-deficient metastatic colorectal cancer. Oncologist 24: 1453-1461, 2019.

81. Wang Z, Zhao J, Wang G, Zhang F, Zhang Z, Zhang F, Zhang Y, Dong H, Zhao X, Duan J, et al: Comutations in DNA damage response pathways serve as potential biomarkers for immune checkpoint blockade. Cancer Res 78: 6486-6496, 2018.

82. Teo MY, Seier K, Ostrovnaya I, Regazzi AM, Kania BE, Moran MM, Cipolla CK, Bluth MJ, Chaim J, Al-Ahmadie H, et al: Alterations in DNA damage response and repair genes as potential marker of clinical benefit from PD-1/PD-L1 blockade in advanced urothelial cancers. J Clin Oncol 36: 1685-1694, 2018.

83. Rodenhuis S, van de Wetering ML, Mooi WJ, Evers SG, van Zandwijk N and Bos JL: Mutational activation of the K-ras oncogene. A possible pathogenetic factor in adenocarcinoma of the lung. N Engl J Med 317: 929-935, 1987. 
84. Slebos RJ, Kibbelaar RE, Dalesio O, Kooistra A, Stam J, Meijer CJ, Wagenaar SS, Vanderschueren RG, van Zandwijk N, Mooi WJ, et al: K-ras oncogene activation as a prognostic marker in adenocarcinoma of the lung. N Engl J Med 323: 561-565, 1990.

85. Ji M, Liu Y, Li Q, Li X, Ning Z, Zhao W, Shi H, Jiang J and Wu C: PD-1/PD-L1 expression in non-small-cell lung cancer and its correlation with EGFR/KRAS mutations. Cancer Biol Ther 17: 407-413, 2016.

86. Calles A, Liao X, Sholl LM, Rodig SJ, Freeman GJ, Butaney M, Lydon C, Dahlberg SE, Hodi FS, Oxnard GR, et al: Expression of PD-1 and Its ligands, PD-L1 and PD-L2, in smokers and never smokers with KRAS-mutant lung cancer. J Thorac Oncol 10: 1726-1735, 2015.

87. Peters S, Gettinger S, Johnson ML, Jänne PA, Garassino MC Christoph D, Toh CK, Rizvi NA, Chaft JE, Carcereny Costa E, et al: Phase II trial of atezolizumab as first-line or subsequent therapy for patients with programmed death-ligand 1-selected advanced non-small-cell lung cancer (BIRCH). J Clin Oncol 35: 2781-2789, 2017.

88. Kato S, Han SY, Liu W, Otsuka K, Shibata H, Kanamaru R and Ishioka C: Understanding the function-structure and function-mutation relationships of p53 tumor suppressor protein by high-resolution missense mutation analysis. Proc Natl Acad Sci USA 100: 8424-8429, 2003

89. Dong ZY, Zhong WZ, Zhang XC, Su J, Xie Z, Liu SY, Tu HY, Chen HJ, Sun YL, Zhou Q, et al: Potential predictive value of TP53 and KRAS mutation status for response to PD-1 blockade immunotherapy in lung adenocarcinoma. Clin Cancer Res 23 3012-3024, 2017.

90. Chabanon RM, Pedrero M, Lefebvre C, Marabelle A, Soria JC and Postel-Vinay S: Mutational landscape and sensitivity to immune checkpoint blockers. Clin Cancer Res 22: 4309-4321, 2016.

91. Strickland KC, Howitt BE, Shukla SA, Rodig S, Ritterhouse LL, Liu JF, Garber JE, Chowdhury D, Wu CJ, D'Andrea AD, et al: Association and prognostic significance of BRCA1/2-mutation status with neoantigen load, number of tumor-infiltrating lymphocytes and expression of PD-1/PD-L1 in high grade serous ovarian cancer. Oncotarget 7: 13587-13598, 2016.

92. Jacome AA and Eng C: Role of immune checkpoint inhibitors in the treatment of colorectal cancer: Focus on nivolumab. Expert Opin Biol Ther 19: 1247-1263, 2019.

93. Song Z, Cheng G, Xu C, Wang W, Shao Y and Zhang Y: Clinicopathological characteristics of POLE mutation in patients with non-small-cell lung cancer. Lung Cancer 118: 57-61, 2018.

94. Mehnert JM, Panda A, Zhong H, Hirshfield K, Damare S, Lane K, Sokol L, Stein MN, Rodriguez-Rodriquez L, Kaufman HL, et al: Immune activation and response to pembrolizumab in POLE-mutant endometrial cancer. J Clin Invest 126 2334-2340, 2016

95. Zhou C, Wu YL, Chen G, Feng J, Liu XQ, Wang C, Zhang S, Wang J, Zhou S, Ren S, et al: Erlotinib versus chemotherapy as first-line treatment for patients with advanced EGFR mutation-positive non-small-cell lung cancer (OPTIMAL, CTONG-0802): A multicentre, open-label, randomised, phase 3 study. Lancet Oncol 12: 735-742, 2011.

96. Sharma P, Hu-Lieskovan S, Wargo JA and Ribas A: Primary, adaptive, and acquired resistance to cancer immunotherapy. Cell 168: 707-723, 2017.

97. Syn NL, Teng MWL, Mok TSK and Soo RA: De-novo and acquired resistance to immune checkpoint targeting. Lancet Oncol 18: e731-e741, 2017.

98. Knutson KL and Disis ML: Tumor antigen-specific T helper cells in cancer immunity and immunotherapy. Cancer Immunol Immunother 54: 721-728, 2005.

99. Cha JH, Chan LC, Li CW, Hsu JL and Hung MC: Mechanisms controlling PD-L1 expression in cancer. Mol Cell 76: 359-370, 2019

100. Lin H, Wei S, Hurt EM, Green MD, Zhao L, Vatan L, Szeliga W, Herbst R, Harms PW, Fecher LA, et al: Host expression of PD-L1 determines efficacy of PD-L1 pathway blockade-mediated tumor regression. J Clin Invest 128: 1708, 2018.

101. Gainor JF, Shaw AT, Sequist LV, Fu X, Azzoli CG, Piotrowska Z, Huynh TG, Zhao L, Fulton L, Schultz KR, et al: EGFR mutations and ALK rearrangements are associated with low response rates to PD-1 pathway blockade in non-small cell lung cancer: A retrospective analysis. Clin Cancer Res 22: 4585-4593, 2016.

102. Hastings K, Yu HA, Wei W, Sanchez-Vega F, DeVeaux M, Choi J, Rizvi H, Lisberg A, Truini A, Lydon CA, et al: EGFR mutation subtypes and response to immune checkpoint blockade treatment in non-small-cell lung cancer. Ann Oncol 30: 1311-1320, 2019.
103. Garassino MC, Gelibter AJ, Grossi F, Chiari R, Soto Parra H, Cascinu S, Cognetti F, Turci D, Blasi L, Bengala C, et al: Italian nivolumab expanded access program in nonsquamous non-small cell lung cancer patients: Results in never-smokers and EGFR-mutant patients. J Thorac Oncol 13: 1146-1155, 2018.

104. Garassino MC, Cho BC, Kim JH, Mazières J, Vansteenkiste J, Lena H, Corral Jaime J, Gray JE, Powderly J, Chouaid C, et al: Durvalumab as third-line or later treatment for advanced non-small-cell lung cancer (ATLANTIC): An open-label, single-arm, phase 2 study. Lancet Oncol 19: 521-536, 2018

105. Su S, Dong ZY, Xie Z, Yan LX, Li YF, Su J, Liu SY, Yin K, Chen RL, Huang SM, et al: Strong programmed death ligand 1 expression predicts poor response and de novo resistance to EGFR tyrosine kinase inhibitors among NSCLC patients with EGFR mutation. J Thorac Oncol 13: 1668-1675, 2018

106. Briscoe J, Guschin D, Rogers NC, Watling D, Müller M, Horn F, Heinrich P, Stark GR and Kerr IM: JAKs, STATs and signal transduction in response to the interferons and other cytokines. Philos Trans R Soc Lond B Biol Sci 351: 167-171, 1996

107. Shin DS, Zaretsky JM, Escuin-Ordinas H, Garcia-Diaz A, Hu-Lieskovan S, Kalbasi A, Grasso CS, Hugo W, Sandoval S, Torrejon DY, et al: Primary resistance to PD-1 blockade mediated by JAK1/2 mutations. Cancer Discov 7: 188-201, 2017.

108. Garcia-Diaz A, Shin DS, Moreno BH, Saco J, Escuin-Ordinas H, Rodriguez GA, Zaretsky JM, Sun L, Hugo W, Wang X, et al: Interferon receptor signaling pathways regulating PD-L1 and PD-L2 expression. Cell Rep 29: 3766, 2019.

109. Massacesi C, di Tomaso E, Fretault $\mathrm{N}$ and Hirawat S: Challenges in the clinical development of PI3K inhibitors. Ann N Y Acad Sci 1280: 19-23, 2013.

110. Mendes RD, Canté-Barrett K, Pieters R and Meijerink JP: The relevance of PTEN-AKT in relation to NOTCH1-directed treatment strategies in T-cell acute lymphoblastic leukemia. Haematologica 101: 1010-1017, 2016.

111. Peng W, Chen JQ, Liu C, Malu S, Creasy C, Tetzlaff MT, Xu C, McKenzie JA, Zhang C, Liang X, et al: Loss of PTEN promotes resistance to T cell-mediated immunotherapy. Cancer Discov 6: 202-216, 2016

112. Roh MR, Gupta S, Park KH, Chung KY, Lauss M, Flaherty KT, Jönsson G, Rha SY and Tsao H: Promoter methylation of PTEN Is a significant prognostic factor in melanoma survival. J Invest Dermatol 136: 1002-1011, 2016.

113. Biton J, Mansuet-Lupo A, Pécuchet N, Alifano M, Ouakrim H, Arrondeau J, Boudou-Rouquette P, Goldwasser F, Leroy K, Goc J, et al: TP53, STK11, and EGFR mutations predict tumor immune profile and the response to Anti-PD-1 in lung adenocarcinoma. Clin Cancer Res 24: 5710-5723, 2018.

114. Skoulidis F, Goldberg ME, Greenawalt DM, Hellmann MD, Awad MM, Gainor JF, Schrock AB, Hartmaier RJ, Trabucco SE, Gay L, et al: STK11/LKB1 mutations and PD-1 inhibitor resistance in KRAS-mutant lung adenocarcinoma. Cancer Discov 8: 822-835, 2018

115. Jamme P, Fernandes M, Copin MC, Descarpentries C, Escande F, Morabito A, Grégoire V, Jamme M, Baldacci S, Tulasne D, et al Alterations in the PI3K pathway drive resistance to MET inhibitors in NSCLC harboring MET exon 14 skipping mutations. J Thorac Oncol 15: 741-751, 2020.

116. Saigi M, Alburquerque-Bejar JJ and Sanchez-Cespedes M: Determinants of immunological evasion and immunocheckpoint inhibition response in non-small cell lung cancer: The genetic front. Oncogene 38: 5921-5932, 2019.

117. Zaretsky JM, Garcia-Diaz A, Shin DS, Escuin-Ordinas H, Hugo W, Hu-Lieskovan S, Torrejon DY, Abril-Rodriguez G, Sandoval S, Barthly L, et al: Mutations associated with acquired resistance to PD-1 blockade in melanoma. N Engl J Med 375: 819-829, 2016

118. Gettinger S, Choi J, Hastings K, Truini A, Datar I, Sowell R, Wurtz A, Dong W, Cai G, Melnick MA, et al: Impaired HLA class I antigen processing and presentation as a mechanism of acquired resistance to immune checkpoint inhibitors in lung cancer. Cancer Discov 7: 1420-1435, 2017.

119. S Saâda-Bouzid E, Defaucheux C, Karabajakian A, Coloma VP, Servois V, Paoletti X, Even C, Fayette J, Guigay J, Loirat D, et al: Hyperprogression during anti-PD-1/PD-L1 therapy in patients with recurrent and/or metastatic head and neck squamous cell carcinoma. Ann Oncol 28: 1605-1611, 2017.

120. Fuentes-Antrás J, Provencio $M$ and Diaz-Rubio E: Hyperprogression as a distinct outcome after immunotherapy. Cancer Treat Rev 70: 16-21, 2018 
121. Kato S, Goodman A, Walavalkar V, Barkauskas DA, Sharabi A and Kurzrock R: Hyperprogressors after immunotherapy: Analysis of genomic alterations associated with accelerated growth rate. Clin Cancer Res 23: 4242-4250, 2017.

122. Mazieres J, Drilon A, Lusque A, Mhanna L, Cortot AB Mezquita L, Thai AA, Mascaux C, Couraud S, Veillon R, et al: Immune checkpoint inhibitors for patients with advanced lung cancer and oncogenic driver alterations: Results from the IMMUNOTARGET registry. Ann Oncol 30: 1321-1328, 2019.

123. Ferrara R, Mezquita L, Texier M, Lahmar J, Audigier-Valette C, Tessonnier L, Mazieres J, Zalcman G, Brosseau S, Le Moulec S, et al: Hyperprogressive disease in patients with advanced non-small cell lung cancer treated with PD-1/PD-L1 inhibitors or with single-agent chemotherapy. JAMA Oncol 4: 1543-1552, 2018.

124. Kim CG, Kim KH, Pyo KH, Xin CF, Hong MH, Ahn BC, Kim Y, Choi SJ, Yoon HI, Lee JG, et al: Hyperprogressive disease during PD-1/PD-L1 blockade in patients with non-small-cell lung cancer. Ann Oncol 30: 1104-1113, 2019.

125. Champiat S, Ferrara R, Massard C, Besse B, Marabelle A, Soria JC and Ferté C: Hyperprogressive disease: Recognizing a novel pattern to improve patient management. Nat Rev Clin Oncol 15: 748-762, 2018

126. Oliner JD, Saiki AY and Caenepeel S: The role of MDM2 amplification and overexpression in tumorigenesis. Cold Spring Harb Perspect Med 6: a026336, 2016.

127. Kato S, Ross JS, Gay L, Dayyani F, Roszik J, Subbiah V and Kurzrock R: Analysis of MDM2 amplification: Next-generation sequencing of patients with diverse malignancies. JCO Precis Oncol 2018: 10.1200/PO.17.00235, 2018.

128. Giusti R, Mazzotta M, Filetti M, Marinelli D, Di Napoli A, Scarpino S, Scafetta G, Mei M, Vecchione A, Ruco L and Marchetti P: CDKN2A/B gene loss and MDM2 alteration as a potential molecular signature for hyperprogressive disease in advanced NSCLC: A next-generation-sequencing approach. J Clin Oncol 37 (15 Suppl): e20628-e20628, 2019.
129. Auslander N, Zhang G, Lee JS, Frederick DT, Miao B, Moll T, Tian T, Wei Z, Madan S, Sullivan RJ, et al: Robust prediction of response to immune checkpoint blockade therapy in metastatic melanoma. Nat Med 24: 1545-1549, 2018.

130. Jiang P, Gu S, Pan D, Fu J, Sahu A, Hu X, Li Z, Traugh N, Bu X, Li B, et al: Signatures of T cell dysfunction and exclusion predict cancer immunotherapy response. Nat Med 24: 1550-1558, 2018.

131. Mezquita L, Auclin E, Ferrara R, Charrier M, Remon J, Planchard D, Ponce S, Ares LP, Leroy L, Audigier-Valette C, et al: Association of the lung immune prognostic index with immune checkpoint inhibitor outcomes in patients with advanced non-small cell lung cancer. JAMA Oncol 4: 351-357, 2018.

132. Harders SW, Balyasnikowa S and Fischer BM: Functional imaging in lung cancer. Clin Physiol Funct Imaging 34: 340-355, 2014.

133. Rossi S, Castello A, Toschi L and Lopci E: Immunotherapy in non-small-cell lung cancer: Potential predictors of response and new strategies to assess activity. Immunotherapy 10: 797-805, 2018.

134. Vrankar M and Unk M: Immune RECIST criteria and symptomatic pseudoprogression in non-small cell lung cancer patients treated with immunotherapy. Radiol Oncol 52: 365-369, 2018.

135. Andrews MC and Wargo JA: Cancer evolution during immunotherapy. Cell 171: 740-742, 2017 International (CC BY-NC-ND 4.0) License. 